\title{
RIGHT ATRIAL MYXOMA ORIGINATING FROM THE TRICUSPID VALVE
}

Hiroaki Kuroda, MD, Kazutoyo Nitta, MD, Yasushi Ashida, MD, Yohichi Hara, MD, Shingo Ishiguro, MD, and Tohru Mori, MD, Yonago, Japan

Myxoma arising from the heart valve is rare. We report here an unusual case of myxoma attached to the tricuspid leaflet, which was successfully treated by partial excision of the leaflet.

A 71-year-old man was admitted with a 1-year history of exertional dyspnea. The electrocardiogram showed atrial flutter and incomplete right bundle branch block, and the chest $\mathrm{x}$-ray film showed mild cardiomegaly. Transthoracic and transesophageal echocardiograms showed a 5 by $4 \mathrm{~cm}$ mass in the right atrium originating from the lower interatrial septum, and prolapsing into the right ventricle through the tricuspid orifice during diastole (Fig. 1). A coronary angiogram showed $75 \%$ stenosis of right coronary artery (RCA) and the small feeding artery from the RCA.

The patient underwent operation with the aid of cardiopulmonary bypass. The right atrium contained the giant tumor, which was attached to the septal leaflet of the tricuspid valve close to the anulus. The mass was removed with excision of a small ellipse (about $5 \mathrm{~mm}$ ) of valve leaflet at the base. The leaflet was reapproximated. Coronary artery bypass grafting to the RCA with a saphenous vein graft was added. The patient was weaned from bypass without difficulty, and an intraoperative transesophageal echocardiogram showed no evidence of tricuspid regurgitation. Recovery from the operation was uneventful. A postoperative pulmonary perfusion scintiscan showed no defect. The tumor was rigid, 7 by 5 by $4 \mathrm{~cm}$ in size, and $62 \mathrm{gm}$ in weight. The histologic diagnosis was confirmed to be myxoma, and there were no tumor cells in the excised leaflet.

Primary cardiac valve tumors are uncommon, with an incidence of less than $10 \%$ of all cardiac tumors. In a recent review, ${ }^{1} 56$ valve tumors occurring in 53 patients over a 58-year period were documented. Forty-one of these tumors $(73 \%)$ were fibroelastomas, and five of them (8.9\%) were myxomas. Although myxoma can occur on the tricuspid valve, ${ }^{2,3}$ mitral valve, ${ }^{1,4}$ and pulmonary valve, ${ }^{5}$ it appears that valvular involvement is more common on the right side than on the left side. Cole and associates ${ }^{2}$ summarized the 11 tricuspid valve myxomas. Five of them had tumor attachment on the atrial side of the valves like our case. There seem to be no distinct clinical features that would lead to the diagnosis of involvement of the tricuspid valve. Before the advent of echocardiography, diagnoses of valve tumor were difficult and often made at autopsy. The reports of this rare condition will certainly increase with more cases of even small tumors being referred for evaluation after echocar-

From the Department of Surgery, Tottori University Faculty of Medicine, Yonago, Japan.

J Thorac Cardiovasc Surg 1995;109:1249-50

Copyright (C) 1995 by Mosby-Year Book, Inc.

$0022-5223 / 95 \$ 3.00+0 \quad \mathbf{1 2 / 8 / 6 0 6 7 7}$

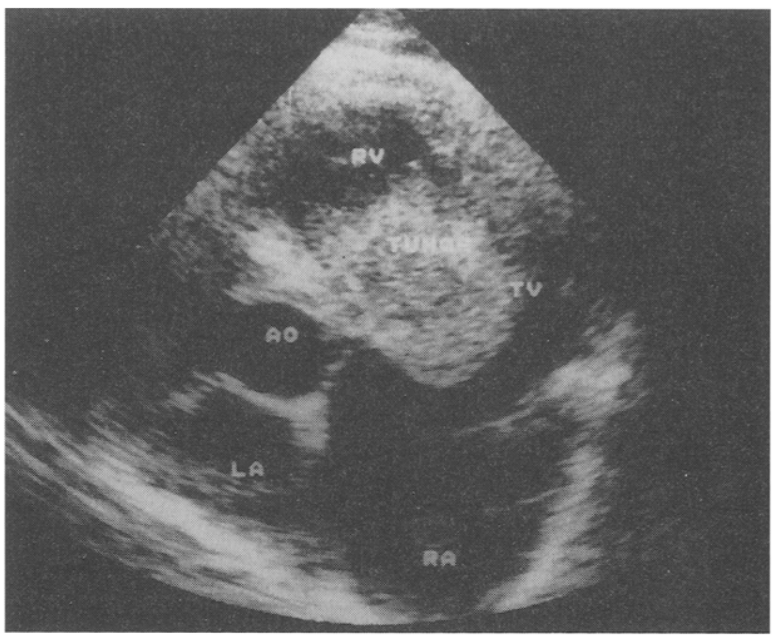

DIASTOLE

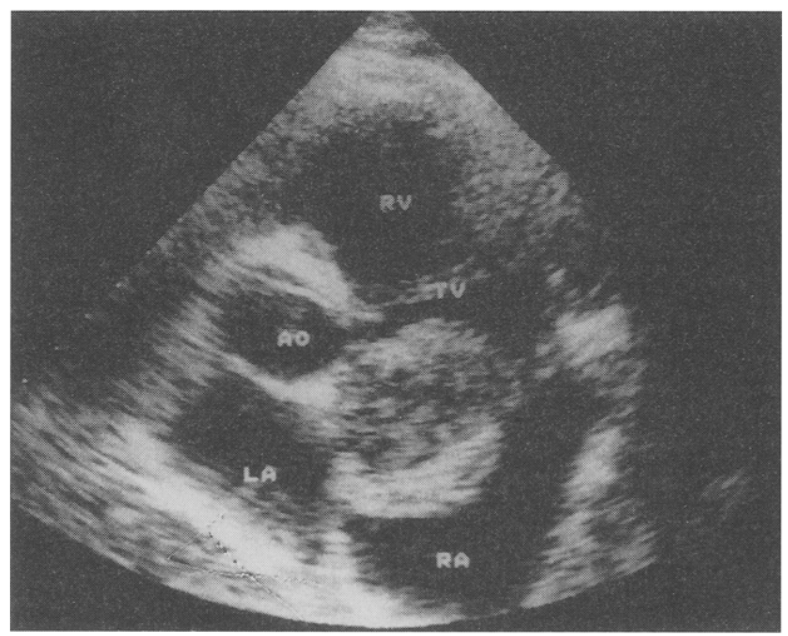

SYSTOLE

Fig. 1. Two-dimensional echocardiogram shows right atrial mass prolapsing into right ventricle during diastole. $R V$, Right ventricle; $T V$, tricuspid valve; $A O$, aorta; $L A$, left atrium; $R A$, right atrium.

diographic identification. Valve tumors should be managed surgically by complete excision to avoid recurrence of the tumor. In our patient, the location of the tumor on a septal leaflet of the tricuspid valve and its small attachment made conservation of the valve possible. 


\section{REFERENCES}

1. Edwards FH, Hale D, Cohen A, Thompson L, Pezzella T, Virmani R. Primary cardiac valve tumors. Ann Thorac Surg 1991;52:1127-31.

2. Cole DJ, Hendren WG, Sink JD, D'Amato PH. Myxoma attached solely to the tricuspid valve. Am J Cardiol 1989;64:546-7.

3. Suri RK, Pattankar VL, Singh H, Aikat BK, Gujral JS.
Myxoma of the tricuspid valve. Aust N Z J Surg 1978;43:429-32.

4. Sandrasgra FA, Oliver WA, English TAH. Myxoma of the mitral valve. Br Heart J 1979;42:221-3.

5. Catton RW, Guntheroth WG, Reichenbach DD. A myxoma of the pulmonary valve causing severe stenosis in infancy. Am Heart J 1963;66:248-52.

\title{
THE EFFECTS OF THE RATE OF REOXYGENATION ON THE RECOVERY OF HYPOXEMIC HEARTS
}

\author{
Antonio Corno, MD, ${ }^{\mathrm{a}}$ Michele Samaja, $\mathrm{PhD},{ }^{\mathrm{b}}$ Stefania Casalini, $\mathrm{PhD},{ }^{\mathrm{b}}$ and Sonia Allibardi, $\mathrm{PhD},{ }^{\mathrm{c}}$ Milan, Italy
}

The myocardial damage induced by the "reoxygenation phenomenon" of hypoxic hearts is well known from both experimental ${ }^{1-4}$ and clinical $^{5}$ reports. The surgical repair of cyanotic congenital heart defects in infants may be complicated by the problem of acute reoxygenation at the beginning of cardiopulmonary bypass (CPB). ${ }^{5}$ In fact, at the onset of CPB the whole body and, therefore, the myocardium are suddenly perfused from the arterial line with an oxygen saturation and an oxygen tension $\left(\mathrm{PO}_{2}\right)$ (generally $>200 \mathrm{~mm} \mathrm{Hg}$ ) substantially higher than the baseline value because of the underlying cyanotic congenital heart defect. The main responsibility for the heart injury has been clinically associated with the burst of oxygen-derived free radicals when cyanotic hearts are suddenly exposed to high oxygen pressures. ${ }^{5}$

To test the hypothesis that the rate of reoxygenation may be critical in the observed pattern, we performed an experimental study in which isolated rat hearts were exposed to acute hypoxia and then underwent either "fast" or "slow" reoxygenation: the recovery of ventricular performance was then compared with the mode of the reoxygenation. Isolated rat hearts, perfused with KrebsHenseleit buffer with a coronary flow of $15 \mathrm{ml} / \mathrm{min},{ }^{3}$ after a period of stabilization with $100 \%$ oxygen saturation, were exposed to 20 minutes of hypoxic perfusion (coronary flow of $15 \mathrm{ml} / \mathrm{min}$, oxygen saturation $10 \%$ of baseline). Reoxygenation was either "fast" $\left(\mathrm{PO}_{2}\right.$ increase $>200$ $\mathrm{mm} \mathrm{Hg} / \mathrm{sec}$ ) or "slow" ( $\mathrm{PO}_{2}$ increase $2 \mathrm{~mm} \mathrm{Hg} / \mathrm{sec}$ ).

The results (Table I) indicate that both the systolic and diastolic ventricular functions were more depressed after "fast" reoxygenation than after "slow" reoxygenation. Although it is difficult to transfer results gathered in an isolated heart preparation to an in vivo situation, from this

From Hospital "S. Donato,"a University of Milan, ${ }^{\mathrm{b}}$ and Scientific Institute "S. Raffaele," Milan, Italy.

J THORAC CARdiovasc Surg 1995;109:1250-1

Copyright (C) 1995 by Mosby-Year Book, Inc.

$0022-5223 / 95 \$ 3.00+0 \quad \mathbf{1 2 / 8 / 5 9 3 5 9}$
Table I

\begin{tabular}{lccc}
\hline & & $p$ \\
& Fast & Value & Slow \\
\hline$n$ & 5 & & 5 \\
Rate of reoxygenation (mm Hg/sec) & 200 & & 2 \\
Recovery (\% of baseline) & & & \\
$\quad$ Developed pressure & $46 \pm 7$ & 0.1 & $62 \pm 5$ \\
$\quad+\mathrm{dP} / \mathrm{dt}$ & $48 \pm 5$ & 0.005 & $70 \pm 3$ \\
$\quad-\mathrm{dP} / \mathrm{dt}$ & $48 \pm 10$ & $\mathrm{NS}$ & $61 \pm 4$ \\
$\quad$ Oxygen uptake & $57 \pm 8$ & $\mathrm{NS}$ & $68 \pm 9$ \\
Change over baseline & & & \\
$\quad$ End-diastolic pressure (mm Hg) & $40 \pm 9$ & 0.09 & $22 \pm 3$ \\
$\quad$ Coronary pressure (mm Hg) & $37 \pm 18$ & $\mathrm{NS}$ & $28 \pm 7$ \\
\hline
\end{tabular}

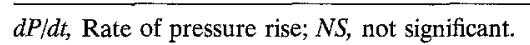

experimental study it appears that (1) gradual reoxygenation after hypoxia may contribute to the reduction of myocardial injury in infants with cyanosis who undergo cardiac repair with the use of $\mathrm{CPB}$; (2) the persisting myocardial dysfunction after reoxygenation underlines the presence of factors responsible for the reoxygenation damage other than oxygen free radicals ${ }^{3}$; (3) the bulk of the injury may be associated with events that occur not only during the reoxygenation, but most likely also during hypoxia, such as the high energy demand ${ }^{4}$; and (4) other experimental and clinical studies are required to learn how to prevent or reduce the reoxygenation phenomenon.

We are already aware of other centers of pediatric cardiac surgical care in which CPB in infants with cyanosis is routinely initiated with an arterial $\mathrm{PO}_{2}$ ( 80 to $100 \mathrm{~mm}$ $\mathrm{Hg}$ ) lower than that generally used and maintained at a relatively lower value (maximum $120 \mathrm{~mm} \mathrm{Hg}$ ) than that conventionally used (Pedro Del Nido, personal communication, 1994).

\section{REFERENCES}

1. Guarnieri C, Flamigni F, Caldarera CM. Role of oxygen in the cellular damage induced by reoxygen- 